\title{
Where Does the Developing Brain Obtain Its Docosahexaenoic Acid? Relative Contributions of Dietary $\alpha$-Linolenic Acid, Docosahexaenoic Acid, and Body Stores in the Developing Rat
}

\author{
WILLIAM LEFKOWITZ, SUN-YOUNG LIM, YUHONG LIN, AND NORMAN SALEM, JR. \\ Uniformed Services University of the Health Sciences [W.L.], Bethesda, MD 20814; Laboratory of \\ Membrane Biochemistry and Biophysics [W.L., Y.L., N.S.], National Institute on Alcohol Abuse and \\ Alcoholism, National Institutes of Health, Rockville, MD 20852; and Division of Ocean \& Science \\ [S.-Y.L.], Korea Maritime University, Busan, 606-791, Korea
}

\begin{abstract}
Docosahexaenoic acid (DHA), a 22-carbon, highly unsaturated, n-3 fatty acid, is important for optimal nervous system function. In this study, designed to quantify how preformed dietary DHA regulates metabolic pathways in vivo, 8-d-old rat pups were divided into four groups and fed artificial rat milk diets. One group was fed formula with deuterium-labeled LNA (d5-LNA) as the only source of n-3 fatty acids, and a second group was fed formula that contained d5-LNA and unlabeled DHA. Two additional groups were dam-reared to permit analysis of fatty acyl pool sizes at postnatal days 8 and 28. The dams were fed a diet that contained 3\% unlabeled LNA. DHA in brain and liver was analyzed. Our study demonstrated that preformed DHA in the diet markedly decreased the amount of biosynthesized DHA that accumulated in the brain and the liver. Surprisingly, $\sim 40 \%$ of the DHA that was newly acquired during this period in the "LNA" group was unlabeled. Because there were no unlabeled $n-3$ fatty acids in this diet, this DHA must have been
\end{abstract}

\section{ABSTRACT}

derived from body stores of $\mathrm{n}-3$ fatty acids. Thus, body stores can be a significant source of brain DHA in animals that are fed LNA as the only source of n-3 fatty acids. (Pediatr Res 57: 157-165, 2005)
AA, arachidonic acid
Abbreviations
DHA, docosahexaenoic acid
d5-DHA, deuterium-labeled docosahexaenoic acid
d5-LNA, deuterium labeled $\alpha$-linolenic acid
DPAn-6, docosapentaenoic acid
EE, ethyl ester
EPA, eicosapentaenoic acid
GC, gas chromatography
LCP, long-chain polyunsaturate
LNA, $\alpha$-linolenic acid
MS, mass spectrometry

Docosahexaenoic acid (DHA) is a 22-carbon, highly unsaturated, n-3 fatty acid that accumulates in high concentrations in the brain and the retina. It is known that DHA is important for optimal nervous system function as significant deficiency states are associated with decreased behavioral function in animal models (1-8). N-3 fatty acids are essential nutrients for mammals, that is, they cannot be synthesized de novo. However, longer chain n-3 fatty acids such as DHA can be biosynthesized in mammals from n-3 fatty acid precursors such as the 18-carbon n-3 fatty acid $\alpha$-linolenic acid (LNA) (9-13).

Received March 29, 2004; accepted June 30, 2004.

Correspondence: Norman Salem, Jr., Ph.D., 12420 Parklawn Drive, Room 1-14, Rockville, MD 20852; e-mail: nsalem@niaaa.nih.gov

This project was supported by the Intramural Research Program of the National Institute on Alcohol Abuse and Alcoholism, National Institutes of Health.

DOI: 10.1203/01.PDR.0000147572.57627.AE
An important question for essential fatty acid nutrition has been whether preformed dietary DHA is required or needs can be met with its precursor LNA. Although breast milk always contains DHA (14), until 2002, no infant formula that contained DHA was available in North America as n-3 fatty acids were supplied only in the form of LNA.

Whether it is reasonable to expect metabolism of LNA to supply all of the DHA needed for brain and other organ growth remains unclear. Data from previous tracer studies show a marked neural tissue preference for preformed DHA over metabolized LNA during development $(15,16)$. Furthermore, animals that ingest diets with high levels of LNA are unable to reach brain DHA levels of animals that ingest DHA (17-19).

This study therefore was designed to quantify the amount of brain and liver DHA derived from biosynthesis when preformed DHA was or was not available in the diet. It has been suggested that liver microsomes will decrease the amount of 
LNA that they convert to DHA in the presence of preformed DHA (20). Our hypothesis was that preformed dietary DHA would decrease the amount of LNA to DHA biosynthesis in vivo during rat development.

In this experiment, all dietary LNA was labeled with deuterium such that any DHA derived from metabolism would also be labeled with deuterium. This allowed for quantification of the total amount of DHA derived from metabolism over the duration of the study by direct measurement of the deuteriumlabeled DHA. A new method for separation and quantification of deuterium-labeled n-3 fatty acids using gas chromatography is also presented and validated in this article.

The rat is a good model for assessing n-3 fatty acid metabolism for several reasons. First, rats seem to possess the same enzymatic pathways for $\mathrm{n}-3$ metabolism as humans. Second, the majority of rat brain growth, or the "brain growth spurt," starts after birth and takes place during the first few weeks of life (21). This rat brain growth spurt roughly mimics the human brain growth spurt that occurs from $\sim 28$ wk gestation to $2-3$ y of age, and rat brain development at 1 wk after birth may be comparable to human brain development at term (21). The impact of a diet on human neurodevelopment can be modeled by controlling the diet using an artificial feeding approach during the few short weeks of the brain growth spurt in the rat. As a result, the rat has been a convenient and well-studied animal model of n-3 fatty acid metabolism.

\section{METHODS}

Study design. For studying the effects of preformed dietary DHA on the metabolism of n-3 fatty acids, two artificial rat milk diets were fed. Artificial rat milk was used so that the fatty acid composition could be completely controlled. Both milks contained LNA, all of which was labeled with deuterium, as ${ }^{2} \mathrm{H}_{5}-17,17,18,18,18-18: 3 n-3$ ethyl ester [d5-LNA; Cambridge Isotope Labs, Andover, MA; analyzed by gas chromatography/mass spectrometry (GC/MS) to be $>98 \%$ d5-LNA]. In this way, any DHA that was derived from biosynthesis would also be labeled with deuterium as ${ }^{2} \mathrm{H}_{5}-21,21,22,22,22$ 22:6n-3 (d5-DHA). The "LNA" milk contained d5-LNA as its only n-3 fatty acid source. The "LNA+DHA" milk contained the same amount of d5-LNA and additionally contained unlabeled DHA (Table 1).

Rat pups were dam-reared until $8 \mathrm{~d}$ of age. Dams were fed an AIN-93 based pelleted diet that contained $3.1 \%$ LNA as the only n-3 fatty acid source, as described previously $(5,22)$. Pups were divided into groups as described below, and the two experimental diet groups were hand-fed either the LNA milk or the LNA+DHA milk until $28 \mathrm{~d}$ of age. Eight days was chosen as the start time for this experiment because of good success using this method of rearing. Twentyeight days was chosen as an end point because 8-28d encompasses the majority of rat brain growth (21).

Artificial milk. The formulas are based on the Meiji Milk Products Co. (Tokyo, Japan) modular rat formula but with a modified lipid profile (23). The contributions of protein, lipid, and carbohydrate to the dietary energy are 26.3, 68.9 , and $4.8 \mathrm{en} \%$, respectively. The milks are $12 \% \mathrm{wt} / \mathrm{vol}$ lipids composed of saturates (medium-chain triglycerides and hydrogenated coconut oil) and ethyl esters (EE) of unsaturated fatty acids. The LNA milk was designed to contain $40 \%$ saturates, $49 \%$ oleate EE, $10 \%$ linoleate EE, and $1 \%$ d5-LNA EE (expressed as a percentage of total fatty acids), whereas the LNA+DHA milk was to contain $40 \%$ saturates, $47 \%$ oleate EE, $10 \%$ linoleate EE, $1 \%$ d5-LNA $\mathrm{EE}$, and $2 \%$ DHA EE (Table 1). EE in formula have previously been shown to be well absorbed through the gastrointestinal tract after hydrolysis and reesterification $(24,25)$. Methionine was not added; however, the casein and whey protein contained 2.9 and $2.5 \mathrm{wt} \%$ methionine, respectively, thus providing a total methionine content of $0.283 \mathrm{~g} / 100 \mathrm{~mL}$ of milk. The milk was supplemented with $22.5 \mathrm{mg} / 100 \mathrm{~mL}$ of cystine. The casein and whey protein contained 0.4 and $3.6 \mathrm{wt} \%$ cystine, respectively, providing $0.169 \mathrm{~g} / 100 \mathrm{~mL}$ of
Table 1. Composition of artificial rat milk diets

\begin{tabular}{|c|c|c|}
\hline \multirow[b]{2}{*}{ Ingredients } & \multicolumn{2}{|c|}{ Amount (mg/100 mL milk) } \\
\hline & LNA diet & LNA + DHA diet \\
\hline Casein (ALACID, acid casein)* & 6275 & 6275 \\
\hline Whey protein isolate (Alacen 895 )* & 4000 & 4000 \\
\hline Carbohydrate $(\alpha$ lactose $) \dagger$ & 1893 & 1893 \\
\hline Serine $\dagger$ & 28.8 & 28.8 \\
\hline Cystine $\dagger$ & 22.5 & 22.5 \\
\hline Tryptophan $\dagger$ & 27.0 & 27.0 \\
\hline Carnitine $\dagger$ & 4.0 & 4.0 \\
\hline Picolinate $\dagger$ & 2.0 & 2.0 \\
\hline Ethanolamine $\dagger$ & 3.4 & 3.4 \\
\hline Taurine $\dagger$ & 15.0 & 15.0 \\
\hline Vitamin mix (in dextrose) $\ddagger$ & 500 & 500 \\
\hline Tricholine citrate $\dagger$ & 370 & 370 \\
\hline Cholesterol $\dagger$ & 40 & 40 \\
\hline \multicolumn{3}{|l|}{ Minerals } \\
\hline $\mathrm{NaOH} \dagger$ & 2100 & 2100 \\
\hline $\mathrm{KOH}_{\dagger} \dagger$ & 170 & 170 \\
\hline $\mathrm{GlyCaPO}_{4} \dagger$ & 800 & 800 \\
\hline $\mathrm{MgCl}_{2} 6 \mathrm{H}_{2} \mathrm{O} \S$ & 183 & 183 \\
\hline $\mathrm{CaCl}_{2} 2 \mathrm{H}_{2} \mathrm{O} \S$ & 210 & 210 \\
\hline $\mathrm{Ca}_{3} 4 \mathrm{H}_{2} \mathrm{O}$-citrate $\dagger$ & 250 & 250 \\
\hline $\mathrm{Na}_{2} \mathrm{HPO}_{4} \S$ & 114 & 114 \\
\hline $\mathrm{KH}_{2} \mathrm{PO}_{4} \S$ & 51.0 & 51.0 \\
\hline $\mathrm{FeSO}_{4}^{\dagger}$ & 3.0 & 3.0 \\
\hline $\mathrm{ZnSO}_{4} \dagger$ & 6.0 & 6.0 \\
\hline $\mathrm{CuSO}_{4}^{\dagger}$ & 1.6 & 1.6 \\
\hline $\mathrm{MnSO}_{4} \dagger$ & 0.07 & 0.07 \\
\hline $\mathrm{NaF} \dagger$ & 0.16 & 0.16 \\
\hline $\mathrm{KI}_{\dagger}+$ & 0.18 & 0.18 \\
\hline Fat sources & \multicolumn{2}{|c|}{$\mathrm{g} / 100 \mathrm{~mL}$ milk } \\
\hline MCT oildI & 1.56 & 1.56 \\
\hline Coconut oil (hydrogenated)\| & 3.24 & 3.24 \\
\hline 18:1n-9 EE\# & 5.64 & 5.52 \\
\hline 18:2n-6 EE\# & 1.20 & 1.20 \\
\hline d5-18:3n-3 EE** & 0.12 & 0.12 \\
\hline 22:6n-3 EE\# & & 0.24 \\
\hline
\end{tabular}

Component sources were as follows:

* The whey protein isolate used was Alacen 895, and the acid casein was Alacid 710 from NZMP (North America) Inc. (Santa Rosa, CA).

$\dagger$ Sigma-Aldrich Corp. (St. Louis, MO).

\$ Harlan (Madison, WI).

$\S$ Mallinkrodt (Hazelwood, MO).

II Mead Johnson Nutritionals (Evansville, IN).

$\|$ Dyets (Bethlehem, PA).

\# Nu-Chek Prep, Inc. (Elysian, MN).

** Cambridge Isotope Labs (Andover, MA).

milk. Thus, the total milk content was $0.191 \mathrm{~g} / 100 \mathrm{~mL}$ of cystine and provides 0.115 methionine equivalents. The total methionine equivalents thus are similar to that provided by rat milk (23).

A quantity of base milk that would be consumed within $\sim 2$ wk was prepared and divided into $10-\mathrm{mL}$ vials and stored at $5^{\circ} \mathrm{C}$. Analysis of the base milk before the addition of d5-LNA EE and DHA EE showed that unlabeled 18:3n-3 made up $0.01 \mathrm{wt} \%$ of the total fatty acids. The base milk contained all ingredients except d5-LNA EE, DHA EE, and a portion of oleate EE. A mix of oleate EE plus d5-LNA was prepared so that adding $100 \mu \mathrm{L}$ to $10 \mathrm{~mL}$ of base milk could be hand homogenized and create the fatty acid profile of the LNA diet. A similar mixture of oleate EE, d5-LNA EE, and DHA EE was prepared for the LNA+DHA milk, and these mixtures were stored frozen $\left(-20^{\circ} \mathrm{C}\right)$ under nitrogen. Fresh base milk was prepared $10 \mathrm{~d}$ into the experiment.

For minimizing waste, only $24 \mathrm{~h}$ worth of diet was prepared each day. Fatty acid analysis of milk at the beginning and end of the 24-h period confirmed that the fatty acid concentrations remained stable. Pilot work showed that the artificial milk fatty acid profile was stable for at least $72 \mathrm{~h}$. The artificial milk 
fatty acid analysis is shown in Table 2 . There was slightly higher oleate and slightly lower saturated fat content in both experimental diets with respect to their theoretical compositions.

Upon eye opening at postnatal days 14-15 (p14-15), milk was prepared in 30-mL aliquots in 50-mL conical vials and fitted with water-bottle tops so that rats could feed in an ad libitum manner.

Animals. Multiple litters of timed-pregnant, Long-Evans rats (obtained on day 3 of gestation from Charles River, Portage, MI) were fed an AIN-93 diet modified on day 10 of gestation for control of essential fatty acids as previously described (2). This diet contained $3.1 \%$ of fatty acids as unlabeled LNA as the sole source of n-3 fatty acids. Dams were maintained in a conventional animal facility with controlled temperature, humidity, and illumination. Food and water were provided on an ad libitum basis. Seven litters were selected on the basis of birth times within a 12-h window. At p8, four male rats were selected from each litter and divided randomly into four groups of seven rats each. They were matched so that the various groups contained littermates from each dam. The first group was the baseline reference group for fatty acyl compositional studies and was killed on $\mathrm{p} 8$. The second group was returned to the dams to be reared on dam's milk for the remainder of the experiment as a reference point; this entailed cross-fostering of several pups. The third and fourth groups were hand-fed one of the two experimental milks as described below.

Rat pups were placed in cages that were appropriate for size, and the cages were set on a warming pad at $38^{\circ} \mathrm{C}$. During the hand-rearing portion of the experiment ( $\mathrm{p} 8-\mathrm{p} 15)$, rats were hand-fed every 3-4 h (total of seven feedings a day). Hand-feeding was accomplished with a 1-mL tuberculin syringe fitted with a 2-cm length of soft tubing (Cole Parmer Instrument Company, Vernon Hills, IL; C-flex tubing, catalog no. EW-06424-59). The end of the tubing was warmed over a hot plate and molded flat so that it would fit in the rat's mouth over the tongue. To maintain patency, a 27-G straight needle was inserted into the lumen of the tube during the molding process and then removed. Initially, rats licked a drop of milk off the tip of the tubing and eventually developed enough coordination to suck and swallow from the tubing inserted $0.5-1 \mathrm{~cm}$ into their mouths. By varying pressure on the syringe plunger, the rate of milk flow could be adjusted to match the degree of coordination of the individual rat. After eye opening, the rats were transitioned to feeding formula from a water bottle. Anal-genital stimulation took place with each feeding for the first week of the experiment to facilitate voiding and stooling. Feeding volumes were $\sim 0.05-0.08 \mathrm{~mL} / \mathrm{g}$ body weight at $\mathrm{p} 15$ and were adjusted by subjective signs of hunger and stomach fullness (reaching almost $0.2 \mathrm{~mL} / \mathrm{g}$ body weight by $\mathrm{p} 28$ ). Throughout the experiment, the rats seemed healthy and active.

Rats in both experimental diet groups and the dam-reared reference group were weighed each morning after feeding. All rats were fasted for $\sim 12 \mathrm{~h}$ before tissue harvesting. Animals were decapitated, and brains and livers were collected. Tissues were weighed and frozen in dry ice, wrapped in aluminum foil. Once an entire group of animals was harvested, the tissues were transferred to a $-80^{\circ} \mathrm{C}$ freezer until analysis. All animal experiments were per-

Table 2. Fatty acid analysis of the experimental diets

\begin{tabular}{lcc}
\hline & \multicolumn{2}{c}{ Area $\%($ mean \pm SEM $)$} \\
\cline { 2 - 3 } \multicolumn{1}{c}{ Fatty acid } & LNA diet $(n=14)$ & LNA + DHA diet $(n=25)$ \\
\hline $8: 0$ & $9.5 \pm 0.05$ & $9.4 \pm 0.17$ \\
$10: 0$ & $4.7 \pm 0.02$ & $4.5 \pm 0.06$ \\
$12: 0$ & $12.4 \pm 0.03$ & $12.1 \pm 0.15$ \\
$14: 0$ & $5.1 \pm 0.01$ & $5.1 \pm 0.03$ \\
$16: 0$ & $2.8 \pm 0.01$ & $2.8 \pm 0.01$ \\
$18: 0$ & $3.2 \pm 0.01$ & $3.2 \pm 0.02$ \\
Total saturates & $37.6 \pm 0.11$ & $37.1 \pm 0.34$ \\
$18: 1 n-9$ & $51.0 \pm 0.10$ & $49.5 \pm 0.31$ \\
Total monounsaturates & $51.0 \pm 0.10$ & $49.5 \pm 0.31$ \\
$18: 2 n-6$ & $10.3 \pm 0.02$ & $10.4 \pm 0.05$ \\
Total n-6 & $10.3 \pm 0.02$ & $10.4 \pm 0.05$ \\
$18: 3 n-3$ & $<0.01$ & $<0.01$ \\
d5-18:3n-3 & $1.0 \pm 0.03$ & $1.1 \pm 0.02$ \\
22:6n-3 & ND & $2.0 \pm 0.03$ \\
Total n-3 & $1.0 \pm 0.03$ & $3.0 \pm 0.05$
\end{tabular}

ND, not detected, indicates peaks $<0.001$ of total fatty acids. formed under protocols approved by the NIAAA Animal Care and Use Committee and met National Institutes of Health guidelines for the use of animals in research.

Fatty acid analysis. Tissues were first hand-homogenized in BHT-methanol under nitrogen and then chloroform and buffer solution added as per the method of Folch et al. (26). The chloroform extracts were stored at $-80^{\circ} \mathrm{C}$. Tissues analyzed included brain (right half) and liver sections. Methyl esters were prepared using $\mathrm{BF}_{3}$-methanol and analyzed by $\mathrm{GC}$ as previously described (27). A portion of the total lipid extracts from each tissue was transmethylated using $14 \% \mathrm{wt} / \mathrm{vol} \mathrm{BF}_{3}$-methanol at $100^{\circ} \mathrm{C}$ for $120 \mathrm{~m}$ to which hexane was added [25\% vol/vol hexane; modified from Morrison and Smith (28)]. The fatty acid methyl esters were injected into a Hewlett Packard 6890 gas chromatograph in the split mode with a DB-FFAP (J \& W Scientific, La Palma, CA) capillary column (0.25 mm I.D. $\times 30 \mathrm{~m}, 0.25-\mu \mathrm{m}$ film thickness), a flame ionization detector, and hydrogen as carrier gas at a linear velocity of $55 \mathrm{~cm} / \mathrm{s}$. The injector and detector temperatures were set to $240^{\circ} \mathrm{C}$, and the oven temperature program was as follows: $130-175^{\circ} \mathrm{C}$ at $4^{\circ} \mathrm{C} / \mathrm{min}, 175-210^{\circ} \mathrm{C}$ at $1^{\circ} \mathrm{C} / \mathrm{min}, 210-240^{\circ} \mathrm{C}$ at $30^{\circ} \mathrm{C} / \mathrm{min}$, with a final hold of $30 \mathrm{~min}$. The fatty acid methyl ester 22:3n-3 (Nu-Chek Prep, Elysian, MN; $580 \mu \mathrm{g} / \mathrm{sample}$ ) was used as an internal standard. Peaks were identified by comparison with standard mixtures of fatty acids (standard mixture \#462; Nu-Chek Prep) and by comparison with reference group chromatograms. This GC method was used for the simultaneous separation and measurement of both the deuterium-labeled and -unlabeled (endogenous) fatty acid peaks. Brain fatty acid data are reported as milligrams per whole brain, and liver data are reported as milligrams of fatty acid per whole liver. Artificial milk was analyzed for fatty acid content using the method of Lepage and Roy (29) as this is more accurate when shorter chain fatty acids (e.g. 8-12C) occur at appreciable levels.

Statistics. All data were expressed as the mean \pm SEM. Rat growth was tested using repeated measures ANOVA (Statsoft, Tulsa, OK). Body, brain, liver weight, and tissue fatty acid comparisons at p28 were performed using a one-way ANOVA. The analysis was followed by Tukey HSD post hoc test for determination of statistical significance among the three experimental diet groups.

\section{RESULTS}

Animal rearing. Experimental rat growth was slow during the first $48 \mathrm{~h}$ as rats learned to feed, as has been typical for manual feeding experiments. Thereafter, rat growth paralleled that of dam-reared pups (Fig. 1). During artificial rearing, the body weights of the dam-reared (reference group) rats were slightly greater than those of the two hand-fed diet groups $[F(2,17)=4.248, p<0.05$; LNA, $p<$ 0.05 versus dam-reared; LNA+DHA, $p<0.05$ versus dam-reared]. No significant differences were detected between the growths of the two experimental diet groups. The mean body weights at $28 \mathrm{~d}$ were $85.2 \pm 3.7,87.8 \pm 2.4$, and $96.6 \pm 4.8 \mathrm{~g}$ in the LNA and LNA+DHA diets and the reference groups, respectively, and there were no statistically significant differences among the three groups $[F(2,17)$ $=2.475, p=0.114]$. The mean body weight of the 8-d reference group was $14.5 \pm 1.15 \mathrm{~g}$. At $28 \mathrm{~d}$, the brain weights of the dam-reared groups were significantly greater than those of either hand-fed group $[F(2,17)=5.468, p<$ 0.05 ; LNA, $p<0.05$ versus dam-reared; LNA+DHA, $p<0.05$ versus dam-reared]. The mean brain weights were $1.48 \pm 0.04,1.47 \pm 0.01$, and $1.59 \pm 0.07 \mathrm{~g}$ in the LNA and LNA+DHA diets and reference groups, respectively. The mean brain weight of the 8 - $d$ reference rats was $0.73 \pm$ $0.02 \mathrm{~g}$. At $28 \mathrm{~d}$, the brain-to-body weight ratios were 0.0176 $\pm 0.0008,0.0168 \pm 0.0004$, and $0.0166 \pm 0.0006$ for the LNA and LNA+DHA diets and the reference groups, respectively, and there were no statistically significant differ- 


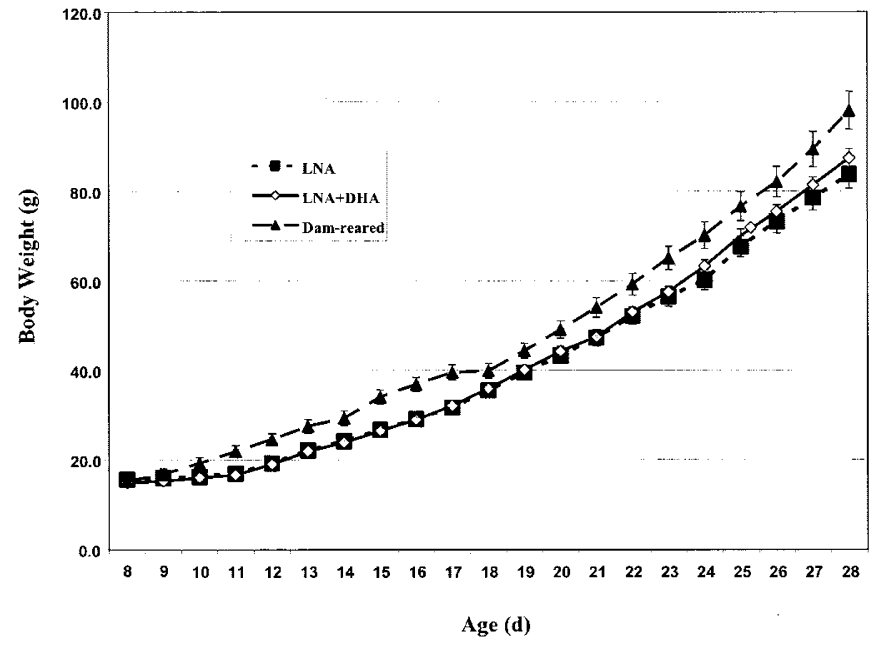

Figure 1. Growth curves of artificially reared and dam-reared rat pups from postnatal days 8 through 28 . $\longrightarrow$, body weights of dam-reared pups; $-\square$, weights of LNA diet pups; — $\longrightarrow$, body weights of LNA+DHA diet pups. Error bars represent SEM. There was no difference in the growth between the two experimental diet groups $(p=0.95)$. Growth of both experimental diet groups differed from dam-reared pup growth $[F(2,17)=4.248, p<0.05$; LNA, $p<0.05 v s$ dam-reared; LNA + DHA, $p<0.05 v s$ dam-reared].

ences among the three groups. There was no statistically significant difference in liver weight at $28 \mathrm{~d}$ among the three groups $[F(2,16)=0.574, p=0.574]$. The mean liver weights were $4.02 \pm 0.24,3.94 \pm 0.11$, and $3.75 \pm 0.13 \mathrm{~g}$ in the LNA and LNA+DHA diets and reference groups, respectively. The mean liver weight of the 8 -d reference group was $0.39 \pm 0.04 \mathrm{~g}$.

Gas chromatographic method and validation. This study is unique in that the amount of stable isotope fed led to accumulation of deuterated fatty acids that were quantitatively on a similar scale as that of the unlabeled fatty acids. There was enough separation in retention times between the labeled and unlabeled n-3 fatty acids such that quantitative measurement of each by GC/FID (flame ionization detector) was possible. The resolution (calculated as proportional to the difference in retention time divided by the mean peak base width) of the d5-DHA and DHA peaks was $1.03 \pm 0.05$ (mean $\pm \mathrm{SD}$ ).

Figure 2 demonstrates the separation of the n-3 fatty acid peaks as well as the respective deuterated peaks in liver samples of rats that were fed the LNA+DHA diet. Both deuterium-labeled and -unlabeled fatty acid peaks are present and separated for $20: 5 n-3,22: 5 n-3$, and 22:6n-3. There was no unlabeled LNA detected in the liver of the rats on the LNA+DHA diet; however, d5-LNA was readily apparent. For retention time comparisons, the $\mathrm{n}-3$ peaks from the liver of a 28-d-old, dam-reared, isotope-free reference rat are overlaid using a broken line.

Figure 3 shows the DHA peaks in the livers across diet groups. Note that the d5-DHA peak is highest in the LNA animals, lower in the LNA+DHA animals, and absent in the dam-reared reference animals.

Verification of the GC method and results is evident from the selected ion chromatograms for brain DHA and d5-DHA presented in Fig. 4. The pentafluorobenzyl (PFB) derivatives
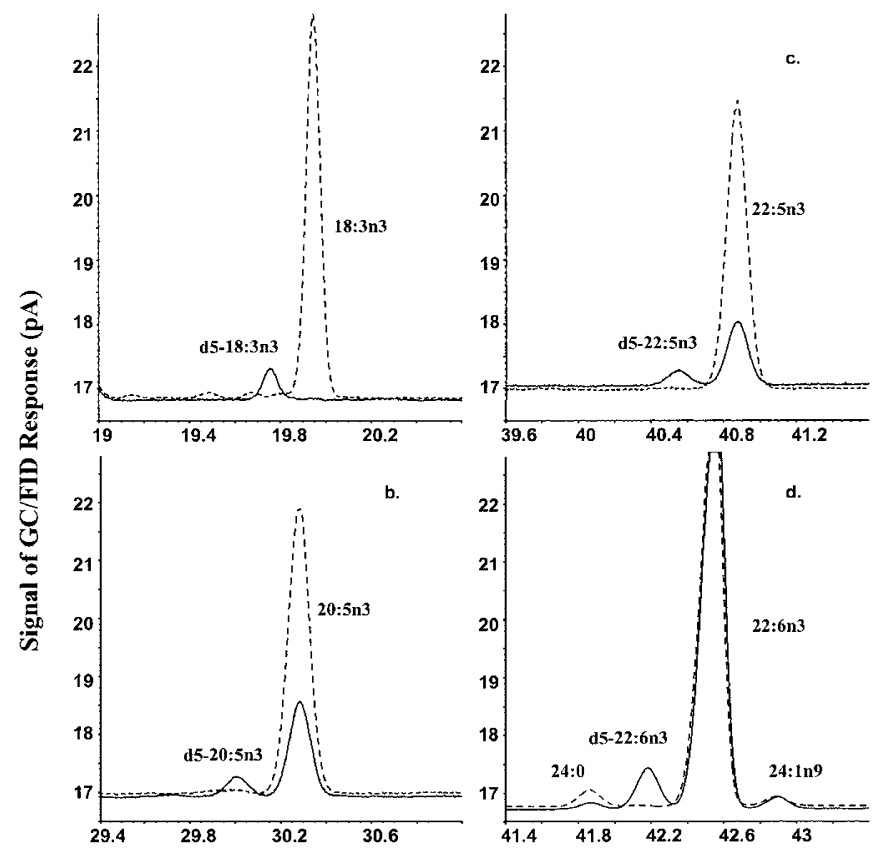

Retention Time (min)

Figure 2. Representative gas chromatograms of liver n-3 fatty acid peaks in the LNA+DHA diet group. The chromatogram of the experimental group is shown with a solid line. A broken line is used to show the chromatogram of the dam-reared reference group for retention time comparison. In $a$ (18:3n-3), there is no unlabeled 18:3n-3 detected in the LNA+DHA liver. The remaining three sections of the chromatogram [20:5n-3 (b), 22:5n-3 (c), and 22:6n-3 (d)] show both unlabeled fatty acid peaks with the same retention times as the dam-reared, isotope-free rats, and deuterated fatty acid peaks, with shorter retention times, that are not present in the dam-reared, isotope-free rats.

were made from the brain lipid extracts and analyzed by negative chemical ionization (NCI) GC/MS as previously described (30). It can be observed that the ratios of the d5- and unlabeled DHA are similar to that presented in Table 3 using the GC method. It is also apparent that the relative intensity of the d5-DHA peak is greatly diminished in the LNA+DHA diet.

Finally, multiple samples were analyzed by NCI GC/MS using pentafluorobenzyl derivitization as described by Pawlosky et al. (30) to confirm the measurements of the deuteriumlabeled $\mathrm{n}-3$ fatty acid peaks determined by GC analysis. NCI GC/MS confirmed the presence of the d5-LNA, d5eicosapentaenoic acid (d5-EPA), d5-22:5n-3 and d5-DHA as the $\mathrm{M}+5$ ion in each case and at a retention time just preceding the unlabeled peaks. The quantitative relationships found by GC analysis were confirmed by demonstrating that the ratios of the areas of the deuterium-labeled and -unlabeled peaks in each case were similar. In addition, calculation of the absolute concentrations, based on respective internal standards, yielded similar values by GC and GC/MS analysis.

Brain. At $8 \mathrm{~d}$, the rat brains contained $\sim 1.6 \mathrm{mg}$ of DHA (Table 3). After 3 wk of feeding the LNA diet, the brain contained an additional $4.0 \mathrm{mg}$ of DHA (5.6 mg total DHA). Of the additional DHA accumulated in the brains of the LNA group animals, $2.4 \mathrm{mg}(60 \%)$ was deuterium labeled, that is, derived from metabolism from dietary d5-LNA. It is interesting that $1.6 \mathrm{mg}(40 \%)$ was unlabeled. In the brains of rats that 


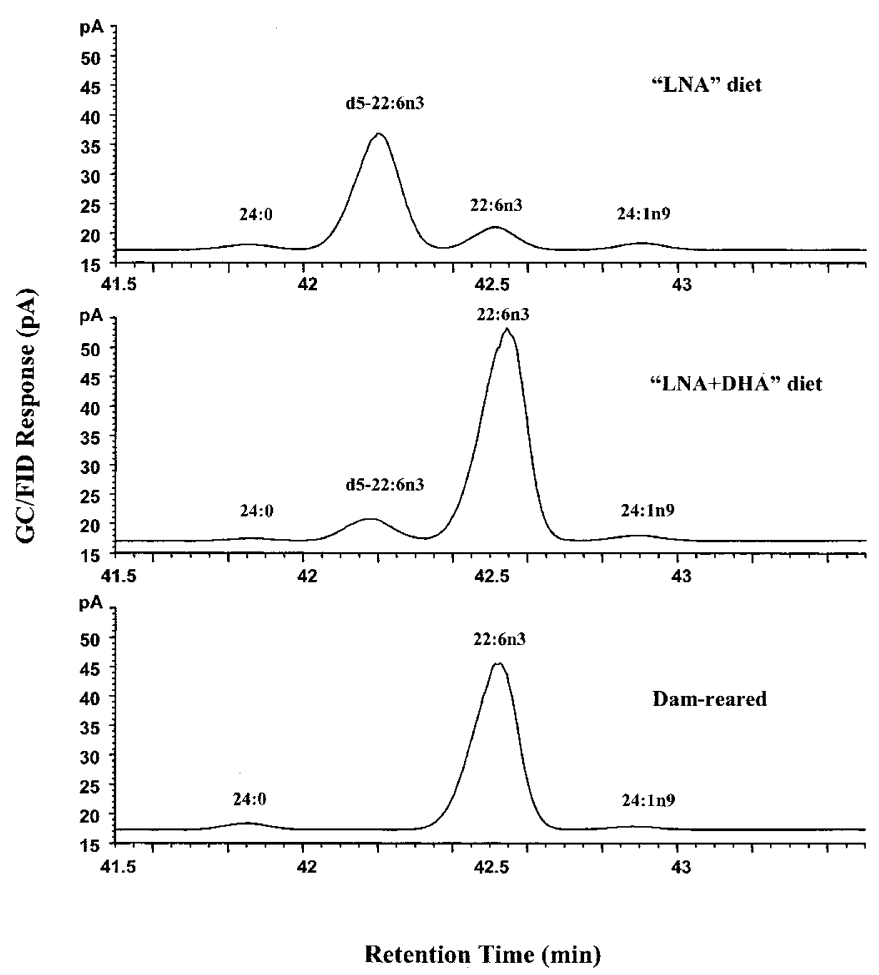

Figure 3. Representative gas chromatograms from the livers of the two diet groups and the dam-reared reference group at $28 \mathrm{~d}$. The four peaks are 24:0, d5-22:6n-3, 22:6n-3, and 24:1n-9, respectively, with the d5-22:6n-3 peak absent in the dam-reared chromatogram.

were fed the LNA+DHA diet, the brains contained an additional $5.4 \mathrm{mg}$ of DHA over the 8 -d reference baseline $(7.0 \mathrm{mg}$ total DHA). In this group, only $0.6 \mathrm{mg}(12 \%)$ of the additional DHA was derived from metabolism, i.e. was deuterium labeled.

The d5-22:5n-3 was significantly greater in the LNA diet with respect to the LNA+DHA diet group. Although only traces of d5-EPA were detected, this intermediate of DHA metabolism was significantly increased in the brains of the LNA+DHA diet group.

Of note, the level of (unlabeled) 22:5n-6 [docosapentaenoic acid (DPAn-6)] in the brain was $0.2 \mathrm{mg}$ at baseline and remained unchanged in the LNA+DHA diet group brains but significantly increased to $1.2 \mathrm{mg}$ in the brains of animals that were fed the LNA diet. There was also a significant $20 \%$ decrease in the content of DHA in the LNA diet with respect to the LNA+DHA diet. Also, there was a slightly lower mean level of total arachidonic acid (AA; 20:4n-6) content of the brains of animals that were fed the LNA +DHA diet, but this change did not reach significance. The content of 22:4n6 was slightly but significantly lower in the LNA+DHA group with respect to the LNA group. The decrease in DHA and concomitant increase in DPAn-6 and other n-6 polyunsaturates in the LNA group reflect the lower available supply of DHA to the nervous system. There were only small changes in the quantities of saturates or monounsaturates in the brains of the rats in either diet group or dam-reared pups.

Liver. Analysis of the liver revealed a similar pattern (Table 4). At $28 \mathrm{~d}$, the livers of the animals that were fed the LNA diet
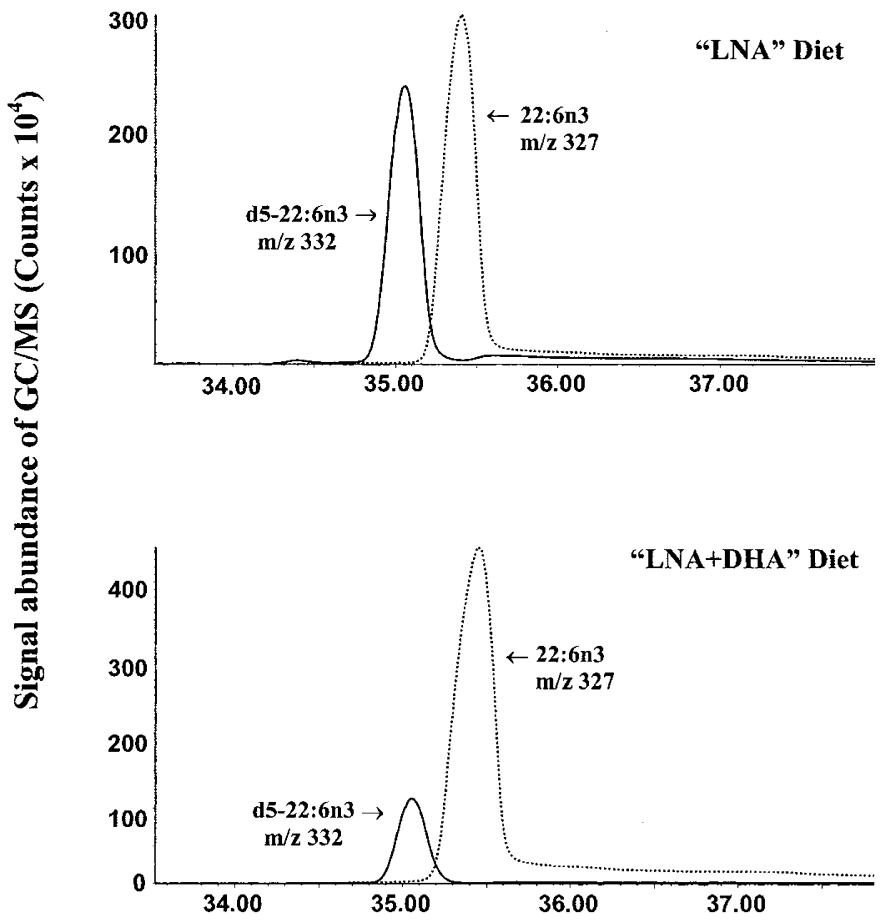

Retention Time (min)

Figure 4. GC/MS analysis of the PFB-derivatized brain extracts from the two experimental diet groups. The selected ion chromatograms for the DHA peaks are presented. The solid line depicts the d5-DHA peak at $\mathrm{m} / \mathrm{z}=332$, and the dashed line depicts the unlabeled DHA at $\mathrm{m} / \mathrm{z}=327$.

contained 4-fold more d5-DHA (40 mg versus $9.9 \mathrm{mg}$, LNA versus $\mathrm{LNA}+\mathrm{DHA})$ and much less unlabeled DHA (5.9 mg versus $87 \mathrm{mg}$, LNA versus LNA+DHA) per whole liver compared with animals that were fed the LNA+DHA diet. In the LNA+DHA diet group, $\sim 10 \%$ of the liver DHA was deuterium labeled $(9.9 \mathrm{mg}$ of d5-DHA and $96.9 \mathrm{mg}$ of total DHA), whereas $87 \%$ of the DHA was deuterium labeled in the LNA diet group (40 mg of d5-DHA and $45.9 \mathrm{mg}$ of total DHA). There was no difference in the content of d5-18:3, but d5-EPA was greater and $\mathrm{d} 5-22: 5 \mathrm{n} 3$ was lower in the LNA+DHA diet with respect to the LNA diet group.

It was of interest to note that the overall liver (unlabeled) DHA concentration had more than doubled when preformed DHA was supplied in the diet. DPAn-6 levels were also significantly higher in the LNA animals ( $27 \mathrm{mg}$ versus $0.7 \mathrm{mg}$, LNA versus LNA+DHA). Although the mean AA level was greater in the LNA group versus the LNA+DHA group, it was not significantly different. However, the level of $22: 4 \mathrm{n}-6$ was significantly greater in the LNA group $(3.5 \mathrm{mg}$ versus $0.8 \mathrm{mg}$, LNA versus $\mathrm{LNA}+\mathrm{DHA})$. Total saturates were the same in both experimental diet groups, but the livers contained less than half of the total amount contained in those of the dam-reared group, in which there was an increased content of 12:0, 14:0, and 16:0. Total monounsaturate content was greatest in the dam-reared group, but there were no significant differences between the two artificially reared groups. 
Table 3. Brain fatty acid composition of the two artificially reared groups and 8-and 28-day-old dam-reared reference groups (mg/whole brain \pm SEM)

\begin{tabular}{|c|c|c|c|c|}
\hline \multirow[b]{2}{*}{ Fatty acid } & \multirow[b]{2}{*}{ 8-day dam-reared } & \multicolumn{3}{|c|}{28 day } \\
\hline & & LNA diet & LNA+DHA diet & Dam-reared \\
\hline 10:0 & $0.02 \pm 0.003$ & $0.06 \pm 0.01^{\mathrm{a}}$ & $0.01 \pm 0.001^{\mathrm{b}}$ & $0.003 \pm 0.002^{\mathrm{b}}$ \\
\hline $14: 0$ & $0.3 \pm 0.01$ & $0.1 \pm 0.006$ & $0.2 \pm 0.04$ & $0.2 \pm 0.02$ \\
\hline $16: 0 \mathrm{dma}$ & $0.3 \pm 0.02$ & $0.6 \pm 0.2$ & $0.8 \pm 0.09$ & $0.4 \pm 0.2$ \\
\hline $16: 0$ & $4.2 \pm 0.1$ & $10.8 \pm 0.2^{\mathrm{ab}}$ & $10.4 \pm 0.2^{\mathrm{a}}$ & $11.3 \pm 0.2^{\mathrm{b}}$ \\
\hline 20:0 & $0.01 \pm 0.0005$ & $0.2 \pm 0.01^{\mathrm{a}}$ & $0.2 \pm 0.01^{\mathrm{ab}}$ & $0.3 \pm 0.01^{\mathrm{b}}$ \\
\hline $22: 0$ & $0.007 \pm 0.0004$ & $0.2 \pm 0.01^{\mathrm{a}}$ & $0.2 \pm 0.01^{\mathrm{ab}}$ & $0.3 \pm 0.01^{\mathrm{b}}$ \\
\hline $24: 0$ & $0.007 \pm 0.0006$ & $0.4 \pm 0.04$ & $0.5 \pm 0.02$ & $0.5 \pm 0.03$ \\
\hline Total saturates & $7.1 \pm 0.2$ & $22.5 \pm 0.7$ & $23.0 \pm 0.4$ & $23.5 \pm 0.6$ \\
\hline $16: 1 \mathrm{n}-7 \mathrm{dma}$ & $0.03 \pm 0.004$ & $0.03 \pm 0.004^{\mathrm{a}}$ & $0.01 \pm 0.002^{\mathrm{b}}$ & $0.01 \pm 0.001^{\mathrm{b}}$ \\
\hline $16: 1 n-7$ & $0.2 \pm 0.005$ & $0.1 \pm 0.004^{\mathrm{a}}$ & $0.2 \pm 0.002^{\mathrm{b}}$ & $0.2 \pm 0.006^{\mathrm{c}}$ \\
\hline $22: 1 n-9$ & $0.002 \pm 0.0002$ & $0.06 \pm 0.003$ & $0.06 \pm 0.003$ & $0.06 \pm 0.004$ \\
\hline $24: 1 n-9$ & $0.01 \pm 0.006$ & $0.7 \pm 0.1$ & $0.6 \pm 0.04$ & $0.6 \pm 0.03$ \\
\hline Total monounsaturates & $2.2 \pm 0.06$ & $10.6 \pm 0.4$ & $11.0 \pm 0.3$ & $11.0 \pm 0.2$ \\
\hline $18: 2 n-6$ & $0.1 \pm 0.006$ & $0.4 \pm 0.01^{\mathrm{a}}$ & $0.5 \pm 0.02^{\mathrm{b}}$ & $0.4 \pm 0.01^{\mathrm{b}}$ \\
\hline $18: 3 n-6$ & $0.009 \pm 0.0004$ & $0.004 \pm 0.0002$ & $0.004 \pm 0.0004$ & $0.004 \pm 0.0003$ \\
\hline $20: 3 n-6$ & $0.06 \pm 0.004$ & $0.2 \pm 0.01^{\mathrm{a}}$ & $0.3 \pm 0.02^{\mathrm{b}}$ & $0.3 \pm 0.01^{\mathrm{b}}$ \\
\hline $20: 4 n-6$ & $1.8 \pm 0.05$ & $5.0 \pm 0.1^{\mathrm{ab}}$ & $4.7 \pm 0.08^{\mathrm{a}}$ & $5.4 \pm 0.1^{\mathrm{b}}$ \\
\hline $22: 4 n-6$ & $0.4 \pm 0.01$ & $1.5 \pm 0.04^{\mathrm{a}}$ & $1.3 \pm 0.03^{\mathrm{b}}$ & $1.6 \pm 0.02^{\mathrm{c}}$ \\
\hline $22: 5 n-6$ & $0.2 \pm 0.006$ & $1.2 \pm 0.03^{\mathrm{a}}$ & $0.3 \pm 0.01^{\mathrm{b}}$ & $0.4 \pm 0.01^{\mathrm{c}}$ \\
\hline Total n-6 & $2.6 \pm 0.08$ & $8.3 \pm 0.2^{\mathrm{a}}$ & $7.0 \pm 0.1^{\mathrm{b}}$ & $8.1 \pm 0.2^{\mathrm{a}}$ \\
\hline d5-18:3n-3 & - & $0.002 \pm 0.0002$ & $0.002 \pm 0.0002$ & - \\
\hline $18: 3 n-3$ & $0.001 \pm 0.0001$ & $\mathrm{ND}^{\mathrm{a}}$ & $\mathrm{ND}^{\mathrm{a}}$ & $0.002 \pm 0.0002^{\mathrm{b}}$ \\
\hline $22: 6 n-3$ & $1.6 \pm 0.05$ & $3.1 \pm 0.1^{\mathrm{a}}$ & $6.3 \pm 0.1^{\mathrm{b}}$ & $6.7 \pm 0.2^{\mathrm{b}}$ \\
\hline Total 22:6n-3 & $1.6 \pm 0.05$ & $5.6 \pm 0.2^{\mathrm{a}}$ & $7.0 \pm 0.1^{b}$ & $6.7 \pm 0.2^{b}$ \\
\hline Total n-3 & $1.6 \pm 0.06$ & $5.6 \pm 0.2^{\mathrm{a}}$ & $7.1 \pm 0.1^{\mathrm{b}}$ & $6.8 \pm 0.2^{\mathrm{b}}$ \\
\hline Total fatty acids & $13.5 \pm 0.4$ & $47.0 \pm 1.3$ & $48.1 \pm 0.9$ & $49.5 \pm 1.0$ \\
\hline
\end{tabular}

$\mathrm{ND}$, not detected, i.e. $<0.001 \mathrm{mg} / \mathrm{brain}$; dma the dimethylacetal derivatives formed from plasmalogenic forms of phospholipids.

Different superscripted letters indicate statistically different values.

\section{DISCUSSION}

A long-standing question in essential fatty acid research has been whether long-chain polyunsaturates (LCPs) are accumulated in tissues via metabolism of 18 -carbon precursors normally abundant in the diet or rather are incorporated directly from preformed dietary LCPs. Many past studies have demonstrated that various pathways, either metabolic or involving preformed LCP intermediates, are operative for various tissues. What has been totally lacking is any approach that could assess the quantitative contributions of the various known pathways for LCP accumulation. One key aspect of this problem is the source of brain DHA because maintenance of its level is critical for optimal neural function $(1-8,31,32)$.

A novel method for assessing the origins of brain DHA is presented in this work. It is based on the concept that, when a nutrient (e.g. LNA) is replaced in its entirety in a synthetic diet by the same compound but in stable isotope form and fed over an extended period of time, metabolites (e.g. DHA) formed from this compound will also be isotope labeled. When the preformed compound (DHA) is then added to the diet, a quantitative evaluation can be made of the relative contributions of metabolism versus incorporation of the preformed LCP by determining the proportion of the LCP that has become labeled with isotope. Those molecules that become labeled originate from deuterated LNA metabolism, whereas the unlabeled compound represents molecules incorporated from the preformed source.

When dietary LNA was replaced with d5-LNA and fed to rat pups from days 8 to 28 of life, surprising results were obtained. It may have been expected that after 3 wk of brain accumula- 
Table 4. Liver fatty acid composition of the two experimental diet groups and the 8-and 28-day-old dam-reared reference groups (mg/whole liver \pm SEM)

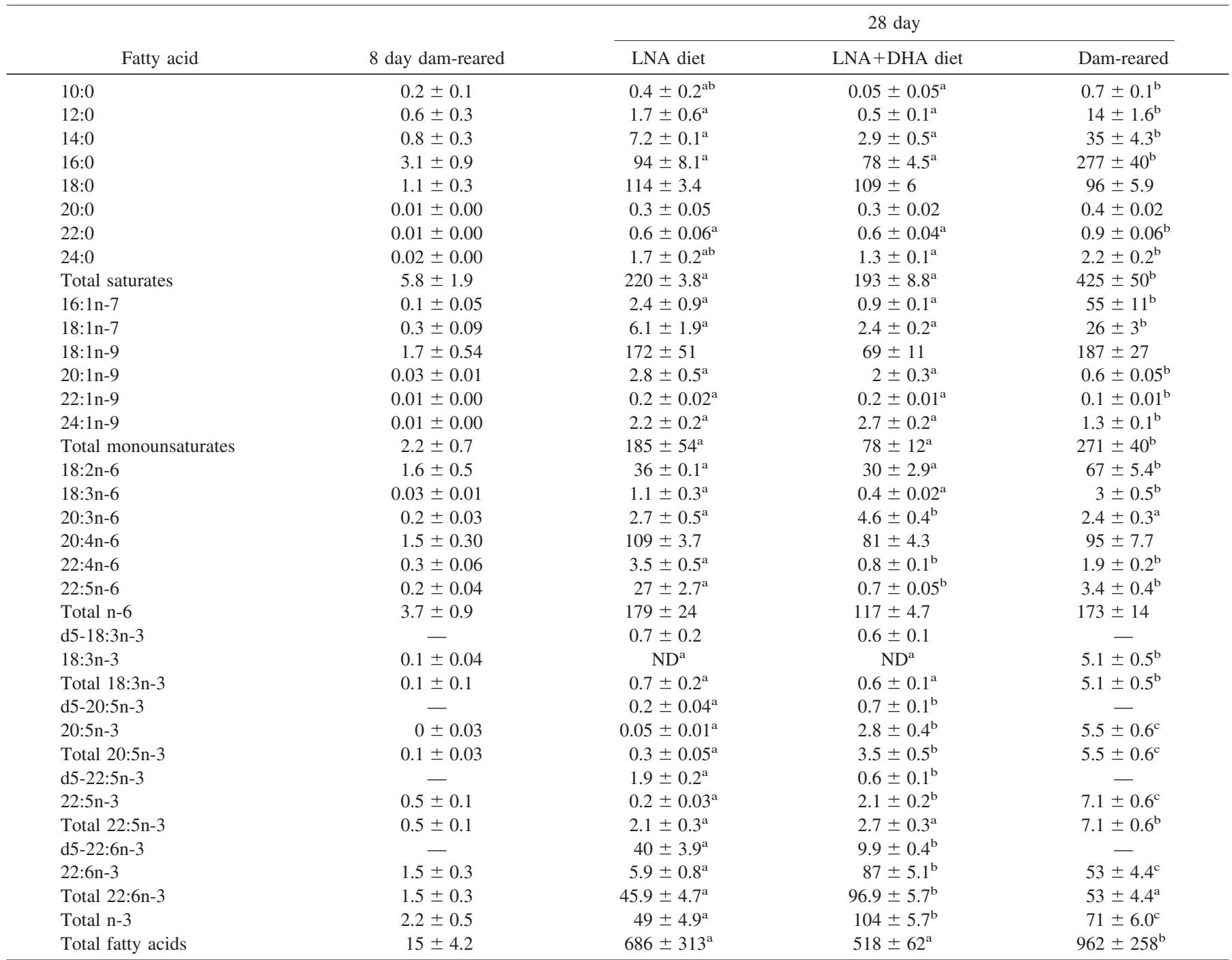

$\mathrm{ND}$, not detected, i.e. $<0.001 \mathrm{mg} /$ whole liver.

Different superscripted letters after SEM indicate statistically different values.

tion of DHA in the absence of dietary DHA, little or none would be unlabeled, i.e. derived from preformed DHA. However, $40 \%$ of the brain DHA was unlabeled, indicating that body stores had been an important source of brain DHA. When DHA is also included in the diet, $88 \%$ of the accumulated brain DHA was unlabeled and thus was derived from preformed DHA. This clearly shows that the rat brain preferentially uses sources of preformed DHA during brain growth. Nevertheless, the role of body stores of DHA was somewhat surprising and may be a result of the inadequacy of LNA metabolism to supply brain requirements during the brain growth spurt. This is consistent with the recently reported nonreciprocal replacement of rat brain DHA by DPAn-6 in the 5- to 20-d postnatal period (33).

Of interest is the question of whether body stores played a similar role for brain DHA supply even in the DHAsupplemented diet. However, because we did not label dietary DHA, we cannot determine the proportions of the unlabeled DHA that is derived from the diet or from body stores. It is likely that the degree to which body stores are available for supply of DHA to the nervous system in turn are dependent on the level of and type of n-3 fatty acids in the maternal diet and the amount and the nature of the resulting body stores in the offspring, as well as the age of the pup (34).

There was a somewhat different response by the liver to dietary DHA as the liver concentration of DHA and total n-3 fatty acids more than doubled with respect to the LNA-only diet. This increased DHA content was nearly all (90\%) composed of unlabeled DHA, indicating that it was due to incorporation of preformed DHA from the diet. This large pool of unlabeled DHA may be one important source of brain DHA in the case in which the diet contained DHA. It is also of interest that the absolute amount of liver d5-DHA decreased by 4-fold, indicating that net DHA synthesis had decreased, perhaps as a result of down-regulation (35). This suggestion is consistent with the recent observations by Pawlosky et al. (36) that human adults who consume a fish-based diet have lower rates 
of conversion of DPAn-3 to DHA than those who consume a beef-based diet.

This method can also be applied to the study of n-6 pathway metabolism providing that diets can be constructed where unlabeled LA is efficiently removed. LA is a frequent contaminant of protein sources, even those that are "defatted," as well as carbohydrate sources such as corn starch. This work also presents a new method for the facile measurement of both the labeled and unlabeled n-3 fatty acids using only GC. This is possible because the stable isotopes are not fed at low levels as in most tracer experiments but comprise all of the dietary LNA. The resulting higher levels of stable isotope products are within the concentration range that can be measured with the flame ionization detector. It is also necessary to have five or more deuterium atoms on the labeled compound to effect baseline separation from the corresponding unlabeled compound on the capillary columns currently available.

One possible difficulty with this approach is due to a possible effect of the deuterium atoms on LNA metabolism in the case in which the d5-LNA occurs at high concentration. Pilot studies have indicated that there are no significant differences between deuterium or C-13 in tracer level experiments in rats in vivo. Also, deuterium atoms are located on the $\mathrm{C} 17$ and $\mathrm{C} 18$ carbons, so they are distant from the reaction sites for elongation and desaturation enzymes. However, the high level of d5-LNA in this experiment may pose some risk that the results may be affected by the presence of isotopes. In that case, it would be expected that a somewhat lower contribution from LNA metabolism to tissue DHA would be obtained here than the actual endogenous rate.

The dietary intervention described in this work also produced changes in brain fatty acid composition. In the brain, there was an increase in DHA and a decrease in many of the n-6 fatty acids, including LA, AA, DTA, and DPAn- 6 , when the diets contained DHA as $2 \%$ of the total fatty acids relative to the LNA diet. This again confirms previous studies that have demonstrated that the brain levels of DHA are higher when preformed DHA is supplied in the diet in comparison with diets that contain only LNA $(15,17,18,37)$.

Although most human breast milk contains $<1 \%$ of fatty acids as DHA, some areas where there is high fish consumption lead to milk levels that exceed $2 \%$ (38). We chose a level of DHA that was $2 \mathrm{wt} \%$ of total fatty acids for this experiment to represent a high but still physiologic level of DHA. For example, a recent study of Japanese adults indicated that the diet contained DHA as $1.28 \%$ of the fatty acids and n-3 LCPs composed $2.22 \%$ of total fatty acids (39). Greenland Eskimos consumed $\sim 5.9 \%$ of fat as DHA with $13.1 \%$ derived from n-3 LCPs; also, their fat intake was considerably higher than most modern diets (40). The two diets in our study represent the two extreme points of the DHA dose-response curve. It will be of interest to determine a more complete dose-response curve with respect to the DHA content of the diet and to determine the sensitivity of the brain DHA composition to lower DHA intakes. Also, a more complete understanding of the relative contributions of LNA metabolism, dietary DHA, and body stores of DHA to n-3 fatty acid tissue deposition could be derived from a more exhaustive study in which other periods of development, differences in maternal diets, and differences between various brain areas in this respect are examined.

From this experiment, it is clear that in animals that are fed an LNA-only, DHA-free diet, body stores can play a significant role in the supply of DHA to the developing brain. This may represent a protective mechanism for brain DHA supply in the face of inconsistent dietary n-3 fatty acid intake. Because preterm infants have a lower amount of body stores of n-3 fatty acids relative to the term infant (41), this may provide a partial explanation for the observations that there is a more consistent benefit of DHA formula supplementation for preterm infants but a smaller and less consistent benefit for term infants $(1,42,43)$. One must also consider that when infants are fed diets that contain only LNA as a source of $n-3$ fatty acids, the flow of preformed DHA from body stores to the brain may be expected to partially deplete body stores. This may have adverse consequences for peripheral organs and nonneural functions.

\section{REFERENCES}

1. Salem N Jr, Litman B, Kim HY, Gawrisch K 2001 Mechanisms of action of docosahexaenoic acid in the nervous system. Lipids 36:945-959

2. Okuyama H, Kobayashi T, Watanabe S 1996 Dietary fatty acids-the N-6/N-3 balance and chronic elderly diseases. Excess linoleic acid and relative N-3 deficiency syndrome seen in Japan. Prog Lipid Res 35:409-457

3. Carrie I, Smirnova M, Clement M, DE JD, Frances H, Bourre JM 2002 Docosahexaenoic acid-rich phospholipid supplementation: effect on behavior, learning ability, and retinal function in control and n-3 polyunsaturated fatty acid deficient old mice. Nutr Neurosci 5:43-52

4. Reisbick S, Neuringer M, Hasnain R, Connor WE 1994 Home cage behavior of rhesus monkeys with long-term deficiency of omega-3 fatty acids. Physiol Behav 55:231-239

5. Moriguchi T, Greiner RS, Salem N Jr 2000 Behavioral deficits associated with dietary induction of decreased brain docosahexaenoic acid concentration. J Neurochem 75:2563-2573

6. Greiner RS, Moriguchi T, Slotnick BM, Hutton A, Salem N 2001 Olfactory discrimination deficits in $\mathrm{n}-3$ fatty acid-deficient rats. Physiol Behav 72:379-385

7. Catalan J, Moriguchi T, Slotnick B, Murthy M, Greiner RS, Salem N Jr 2002 Cognitive deficits in docosahexaenoic acid-deficient rats. Behav Neurosci 116:1022-1031

8. Ahmad A, Murthy M, Greiner RS, Moriguchi T, Salem N Jr 2002 A decrease in cell size accompanies a loss of docosahexaenoate in the rat hippocampus. Nutr Neurosci 5:103-113

9. Emken EA, Adlof RO, Rakoff H, Rohwedder WK, Gulley RM 1990 Metabolism in vivo of deuterium-labelled linolenic and linoleic acids in humans. Biochem Soc Trans 18:766-769

10. Salem N Jr, Wegher B, Mena P, Uauy R 1996 Arachidonic and docosahexaenoic acids are biosynthesized from their 18-carbon precursors in human infants. Proc Natl Acad Sci USA 93:49-54

11. Carnielli VP, Wattimena DJ, Luijendijk IH, Boerlage A, Degenhart HJ, Sauer PJ 1996 The very low birth weight premature infant is capable of synthesizing arachidonic and docosahexaenoic acids from linoleic and linolenic acids. Pediatr Res 40:169-174

12. Sauerwald TU, Hachey DL, Jensen CL, Heird WC 1997 New insights into the metabolism of long chain polyunsaturated fatty acids during infancy. Eur J Med Res 2:88-92

13. Su HM, Huang MC, Saad NM, Nathanielsz PW, Brenna JT 2001 Fetal baboons convert $18: 3 n-3$ to $22: 6 n-3$ in vivo. A stable isotope tracer study. J Lipid Res 42:581-586

14. Innis SM 1992 Human milk and formula fatty acids. J Pediatr 120:S56-S61

15. Sinclair AJ 1975 Incorporation of radioactive polyunsaturated fatty acids into liver and brain of developing rat. Lipids 10:175-184

16. Su HM, Bernardo L, Mirmiran M, Ma XH, Corso TN, Nathanielsz PW, Brenna JT 1999 Bioequivalence of dietary alpha-linolenic and docosahexaenoic acids as sources of docosahexaenoate accretion in brain and associated organs of neonatal baboons. Pediatr Res 45:87-93

17. Woods J, Ward G, Salem N Jr 1996 Is docosahexaenoic acid necessary in infant formula? Evaluation of high linolenate diets in the neonatal rat. Pediatr Res 40:687694

18. Abedin L, Lien EL, Vingrys AJ, Sinclair AJ 1999 The effects of dietary alphalinolenic acid compared with docosahexaenoic acid on brain, retina, liver, and heart in the guinea pig. Lipids 34:475-482

19. Bowens RA, Clandinin MT 2000 High dietary 18:3n- 3 increases the $18: 3 n-3$ but not the $22: 6 n-3$ content in the whole body, brain, skin, epididymal fat pads, and muscles of suckling rat pups. Lipids 35:389-394

20. Brenner RR, Peluffo RO 1967 Inhibitory effect of docosa-4,7,10,13,16,19-hexaenoic acid upon the oxidative desaturation of linoleic into gamma-linolenic acid and of 
alpha-linolenic into octadeca-6,9,12,15-tetraenoic acid. Biochim Biophys Acta 137:184-186

21. Dobbing J 1990 Vulnerable periods in developing brain. In: Dobbin J (ed) Brain, Behaviour, and Iron in the Infant Diet. Springer Verlag, London, pp 1-17

22. Ward G, Woods J, Reyzer M, Salem N Jr 1996 Artificial rearing of infant rats on milk formula deficient in $\mathrm{n}-3$ essential fatty acids: a rapid method for the production of experimental n-3 deficiency. Lipids 31:71-77

23. Kanno T, Koyanagi N, Katoku Y, Yonekubo A, Yajima T, Kuwata T, Kitagawa H, Harada E 1997 Simplified preparation of a refined milk formula comparable to rat's milk: influence of the formula on development of the gut and brain in artificially reared rat pups. J Pediatr Gastroenterol Nutr 24:242-252

24. Harris WS, Hustvedt BE, Hagen E, Green MH, Lu G, Drevon CA 1997 N-3 fatty acids and chylomicron metabolism in the rat. J Lipid Res 38:503-515

25. Hamazaki T, Urakaze M, Makuta M, Ozawa A, Soda Y, Tatsumi H, Yano S, Kumagai A 1987 Intake of different eicosapentaenoic acid-containing lipids and fatty acid pattern of plasma lipids in the rats. Lipids 22:994-998

26. Folch AC, Lees M, Sloane-Stanley GM 1957 A simple method for isolation and purification of total lipids from animal tissues. J Biol Chem 226:497-509

27. Salem N Jr, Reyzer M, Karanian J 1996 Losses of arachidonic acid in rat liver after alcohol inhalation. Lipids 31(suppl):S153-S156

28. Morrison WR, Smith LM 1964 Preparation of fatty acid methyl esters and dimethylacetals from lipids with boron fluoride-methanol. J Lipid Res 5:600-608

29. Lepage G, Levy E, Ronco N, Smith L, Galeano N, Roy CC 1989 Direct transesterification of plasma fatty acids for the diagnosis of essential fatty acid deficiency in cystic fibrosis. J Lipid Res 30:1483-1490

30. Pawlosky RJ, Sprecher HW, Salem N Jr 1992 High sensitivity negative ion GC-MS method for detection of desaturated and chain-elongated products of deuterated linoleic and linolenic acids. J Lipid Res 33:1711-1717

31. Lim S-Y, Moriguhci T, Lefkowitz B, Loewke J, Majchrzak S, Hoshiba J, Salem N Jr 2003 Artificial feeding of an n-3 essential fatty acid deficient diet leads to a loss of brain function in the first generation. In: Huang Y-S, Lin S-J, Huang P-C (eds) Essential Fatty Acids and Eicosanoids. American Oil Chemists Society Press, Champaign, IL, pp 122-131
32. Salem N Jr 1989 Omega-3 fatty acids: molecular and biochemical aspects. In: Spiller GA, Scala J (eds) New Protective Roles for Selected Nutrients. Alan R Liss, Inc., New York, pp 109-228

33. Greiner RS, Catalan JN, Moriguchi T, Salem N Jr 2003 Docosapentaenoic acid does not completely replace DHA in n-3 FA-deficient rats during early development. Lipids 38:431-435

34. Chen ZY, Cunnane SC 1992 Early postnatal development in the rat is characterized by accumulation of highly unsaturated triacylglycerols. Pediatr Res 31:47-51

35. Nakamura MT, Cho HP, Clarke SD 2000 Regulation of hepatic delta-6 desaturase expression and its role in the polyunsaturated fatty acid inhibition of fatty acid synthase gene expression in mice. J Nutr 130:1561-1565

36. Pawlosky RJ, Hibbeln JR, Lin Y, Goodson S, Riggs P, Sebring N, Brown GL, Salem N Jr 2003 Effects of beef- and fish-based diets on the kinetics of n-3 fatty acid metabolism in human subjects. Am J Clin Nutr 77:565-572

37. Bowena RA, Clandinin MT 2000 High dietary 18:3n-3 increases the $18: 3 n-3$ but not the 22:6n-3 content in the whole body, brain, skin, epididymal fat pads, and muscles of suckling rat pups. Lipids 35:389-394

38. Jensen RG 1999 Lipids in human milk. Lipids 34:1243-1271

39. Kuriki K, Nagaya T, Tokudome Y, Imaeda N, Fujiwara N, Sato J, Goto C, Ikeda M, Maki S, Tajima K, Tokudome S 2004 Plasma concentrations of (n-3) highly unsaturated fatty acids are good biomarkers of relative dietary fatty acid intakes: a cross-sectional study. J Nutr 133:3643-3650

40. Bang HO, Dyerberg J, Sinclair HM 1980 The composition of the Eskimo food in north western Greenland. Am J Clin Nutr 33:2657-2661

41. Cunnane SC, Francescutti V, Brenna JT, Crawford MA 2000 Breast-fed infants achieve a higher rate of brain and whole body docosahexaenoate accumulation than formula-fed infants not consuming dietary docosahexaenoate. Lipids 35:105-111

42. Makrides M, Neumann MA, Simmer K, Gibson RA 2000 A critical appraisal of the role of dietary long-chain polyunsaturated fatty acids on neural indices of term infants: a randomized, controlled trial. Pediatrics 105:32-38

43. Uauy R, Hoffman DR, Mena P, Llanos A, Birch EE 2003 Term infant studies of DHA and ARA supplementation on neurodevelopment: results of randomized controlled trials. J Pediatr 143:S17-S25 